\title{
Scientist-friendly policies for non-native English-speaking authors: timely and welcome
}

S.M.R. Vasconcelos, M.M. Sorenson and J. Leta
Programa de Educação, Gestão e Difusão em Biociências, Instituto de Bioquímica Médica, Centro de Ciências da Saúde, Universidade Federal do Rio de Janeiro, Rio de Janeiro, RJ, Brasil

\section{Correspondence}

J. Leta

Instituto de Bioquímica Médica CCS, Bloco B, Sala 39, UFRJ

21941-590 Rio de Janeiro, RJ Brasil

E-mail: jleta@bioqmed.ufrj.br ....................

Received December 15, 2006 Accepted April 4, 2007

\begin{abstract}
That English is the lingua franca of today's science is an indisputable fact. Publication in English in international journals is a pre-requisite for a research paper to gain visibility in academia. However, English proficiency appears to be taken for granted in the scientific community, though this language can be a hurdle for a number of authors, particularly from non-native English-speaking countries. The influence of English proficiency on the publication output of Brazilian authors has never been assessed. We report our preliminary data on the relationship between the English proficiency of 51,223 researchers registered in the $\mathrm{CNPq}$ database and their publication output in international journals. We have found that publication rates are higher for those authors with good command of English, particularly written English. Although our research is still underway and our results are preliminary, they suggest that the correlation between written English proficiency and research productivity should not be underestimated. We also present the comments of some Brazilian scientists with high publication records on the relevance of communication skills to the scientific enterprise.
\end{abstract}

\section{Introduction}

It is an indisputable fact that poor writing skills may be considered the Achilles's heel of many non-native English-speaking scientists (1). In a recent Elsevier Editors' Forum on language polishing, Paul Evans, Elsevier's Vice-President of Science and Technology for China, stated that a substantial number of the editors considered that "the publisher should facilitate language polishing, training for non-native English authors or work proactively with universities" (2). Accordingly, communication skills should play a
Key words - Science policy

- Research output

- English proficiency

- International journals

- Scientific writing

- Education role when it comes to getting published in international journals. Authors who have experienced "language revision" as a condition of acceptance of a manuscript know first hand the importance good writing has in getting published.

Although bad writing may not be the sole reason for rejection letters, writing science in this global English scenario can be a hurdle for scientists from non-English-speaking countries (3). The European Journal of Epidemiology has recently published a timely discussion on the relationship among research funding, English proficiency and pub- 
lication output in highly ranked medical journals (4). Their findings suggested that even though research spending was a strong predictor of publication in these journals, some of the countries with high research spending but lower TOEFL scores had "relatively poor publication output". This report caught our attention at the Federal University of Rio de Janeiro (UFRJ), where we are currently conducting a project on the relationship between the English proficiency of Brazilian scientists and time to publication, from the first draft to acceptance (5). Brazil's science has gained visibility in the last 25 years, and this increase is seen in the country's percent share of all publications in ISI-indexed journals, which has increased from 0.4 to $1.6 \%$ during this period (6). However, this percentage is normally interpreted as basically reflecting factors such as number of international collaborations, of active scientists and amount of research funding. Our view, however, is that looking at the Brazilian percentage share of ISI papers from a linguistic point of view may turn out to be a Pandora's box.

\section{Preliminary analysis of Brazilians' publication output and English proficiency}

A database set up upon our request by the Brazilian National Research Council (CNPq) (7) suggests that there may be a relationship between proficiency in written English and number of publications in international journals. The database is a subset of CNPq's large database and includes English proficiency and number of publications from 1997 to 2004. This database covers 51,223 researchers, including junior and senior researchers with a $\mathrm{PhD}$ degree.

Also, interviews with Brazilian researchers from different fields about their notions of the relationship between communication skills and getting published are in progress. In this paper, we present some of the comments made by some researchers with high publication records.

\section{Productivity and communication skills of CNPq researchers}

Among the researchers who published in the period under study, $44 \%$, i.e., 22,757 , rated their own writing skills as "good", whereas $13 \%$, i.e., 6669, rated theirs as

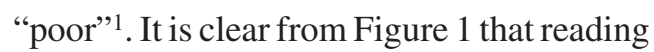
and comprehension are the strongest English skills among Brazilian researchers as compared to writing and speaking.

If we split the 51,223 researchers of the database into 9 groups according to their number of publications in international journals, we find that the fraction of authors with good writing skills increases with the number of papers published in the 4-year time frame (Table 1). As can be seen, this fraction ranges from $53.4 \%$, with $1-2$ publications, to $91.8 \%$, with $>50$ publications. Note that 45 of the 49 researchers with more than 50 papers published are said to have "good writing skills". On the one hand, this particular finding may mean that more experienced writers are well established in academia and get published more easily than novice writers. However, it may mean that "poor writing skills" should not be considered a minor hurdle for Brazilian researchers to get published in international journals.

Although the assessment of writing is based on self-evaluation, which is not a proxy measure and has a subjective nature, the results are intriguing. The apparent correlation between good writing and a greater number of publications suggests that the ability to write in English may influence the

\footnotetext{
1The fraction of authors who rated their writing skills as "reasonable" may be considered a borderline case, and it was not included in this analysis.
} 
visibility of Brazilian research.

\section{Some Brazilian researchers' comments}

As expected for non-native Englishspeaking countries, it is not uncommon for Brazilian scientists to have manuscripts accepted after being revised for language. The task of "brushing up" the English may be time consuming for both junior and senior researchers. Dr. Lewis Greene, editor of the Brazilian Journal of Medical and Biological Research for 26 years, says that $100 \%$ of the papers submitted to the journal in 2003, 99\% of them by non-native English speakers, needed English correction before final acceptance. Professor Martin Schmal, a scientist at the Catalysis Center (NUCAT) at UFRJ, is a fellow of the Brazilian Academy of Sciences and one of the first Latin American scientists to win the Alexander von Humboldt award. He says "the time I spend revising the English of manuscripts by students could certainly be devoted to projects and to the scientific enterprise".

The Brazilian physicist Fernando Lázaro, a professor at the Pontifical Catholic University of Rio de Janeiro, has been one of the most cited Brazilian scientists in the last few years. He is a reviewer for several journals, including Applied Physics Letters and Surface Science. He believes that one way whereby Brazilian universities could contribute to the writing/rewriting phase of manuscripts is to offer formal writing courses for graduate students. This idea is shared by Dr. Mayana Zatz, the coordinator of the Center for Human Genome Studies at the University of São Paulo, and author of more than 250 papers on genetic research. Dr. Zatz states that "English proficiency is fundamental for today's scientists". In her opinion, Brazilian universities could offer "highquality instruction in scientific writing" for Brazilian scientists to improve their writing skills.

\section{Scientist-friendly policies for Brazilian researchers: A gap to be filled?}

In several countries, academic writing is part of university curricula. Among those that have these programs are the US, Canada, and some European countries. The US has a large number of writing programs, and writing centers at American universities can be easily found on the Web: Purdue University, Michigan State University, and the University of Wisconsin-Madison, among others. In Canada, the University of Toronto

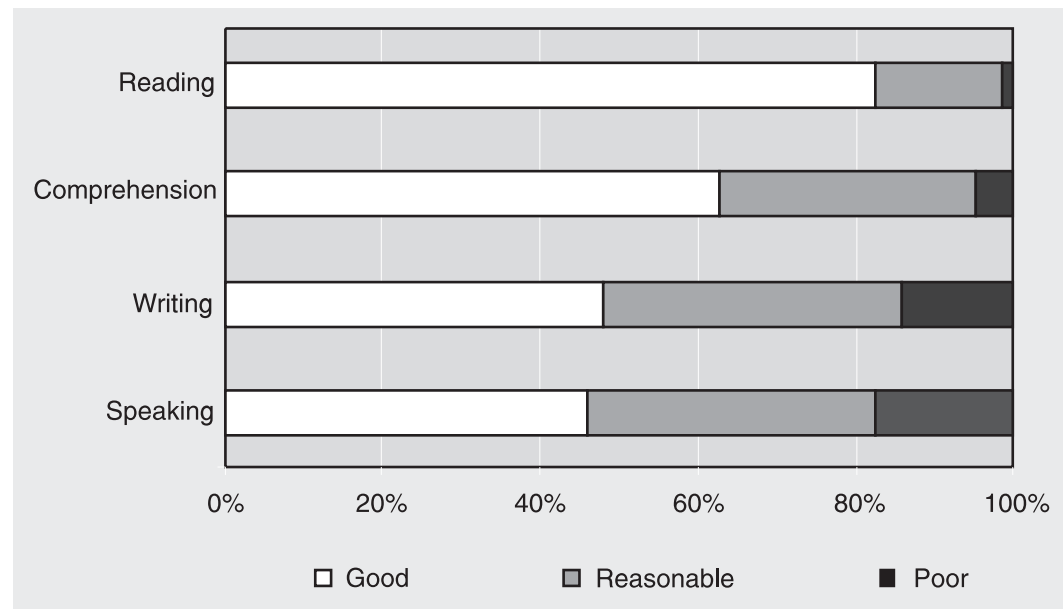

Figure 1. English skills of Brazilian researchers in the CNPq database who published between 2001 and 2004.

Table 1. Distribution of Brazilian researchers according to their English writing skills and number of papers published in international journals (2001-2004).

\begin{tabular}{lrrr}
\hline Publications & All researchers & $\begin{array}{r}\text { Researchers with } \\
\text { good writing skills }\end{array}$ & $\begin{array}{r}\text { Researchers with } \\
\text { poor writing skills }\end{array}$ \\
\hline 0 & 31,157 & $10,191(32.7 \%)$ & $5620(18.0 \%)$ \\
$1-2$ & 9725 & $5197(53.4 \%)$ & $757(7.8 \%)$ \\
$3-5$ & 5091 & $3293(64.7 \%)$ & $201(3.9 \%)$ \\
$6-10$ & 3068 & $2288(74.6 \%)$ & $64(2.1 \%)$ \\
$11-15$ & 1115 & $889(79.7 \%)$ & $16(1.4 \%)$ \\
$16-20$ & 489 & $402(82.2 \%)$ & $7(1.4 \%)$ \\
$21-30$ & 375 & $320(85.3 \%)$ & $1(0.3 \%)$ \\
$31-50$ & 154 & $132(85.7 \%)$ & $3(1.9 \%)$ \\
$>50$ & 49 & $45(91.8 \%)$ & $0(0.0 \%)$ \\
Total & 51,223 & $22,757(44.4 \%)$ & $6669(13.0 \%)$
\end{tabular}

Data taken from the CNPq database and reported as number and percentage. 
provides academic writing instruction for all students regardless of area. With respect to Europe, the European Association for the Teaching of Academic Writing has shown the growing number of European university teachers engaged in developing the writing skills of students and researchers.

In South America, academic writing programs are rare. In Brazil, for instance, a large number of language schools teach only General English. Besides, at the university level, formal training in written English is offered by only a few humanities fields. In the sciences, undergraduate and graduate programs have a more reading-oriented approach, i.e., learning how to write up research in English is not part of the curricula of most Brazilian universities. Indeed, this reading-oriented approach somewhat reflects the language policy adopted by the Brazilian English for Specific Purposes (ESP) National Project, developed between the 1980s and the 1990s. The ESP project was meant to "improve the use of English of Brazilian researchers, science teachers and technicians, especially with regard to reading [our emphasis] specialist and technical publications" (8).

Although reading plays a fundamental part in science and technology, this language policy has left a gap to be filled. Particularly, scientific writing is an essential skill for scientists. Even so, most Brazilian universities appear to overlook the fact that the lack of a clear policy about the acquisition of this skill in graduate programs may be counterproductive. Indeed, Brazilian policy makers have never seriously addressed the issue of writing for publication. Our findings, however, indicate that its importance should not be underestimated. It is worth pointing out that there has been an upward trend in the number of doctoral degrees earned during the past decade in the country. The number of doctoral students graduated in 1991 was 10,496 and in 2001, 32,731 , an increase of $212 \%$ (9). Among other factors, this increase means that more potential authors with or without good command of English will be expected to write well-written manuscripts.

\section{Conclusion}

Although our data are preliminary, they point to a possible relation between publication in international journals and the writing skill of these scientists. Whether or not it affects either the quantity or quality of their publications is an open question. However, we cannot simply overlook this language issue, assuming that it is not of major concern, and focus exclusively on traditional indicators to assess the country's publication output. We are fully aware that a number of factors play a role in this assessment, such as the quality of science itself, amount of research spending, number of active scientists, and number of international collaborations. The importance of these traditional indicators notwithstanding, writing for publication deserves more attention. Particularly, English proficiency, at a time when writing in English is mandatory for researchers, should be better addressed by scientists, educators and policy makers.

In fact, Brazilian universities and funding agencies should consider that language skills, more than ever, play an important role in the doing of science. This is true not only for English but also for Portuguese. Whether this language issue is a priority or not should be judged by all of those who do sound science, have linguistic shortcomings, and cannot rely on in-house editors to make the step of writing up science a less demanding task. We believe that scientist-friendly language policies in Brazil are needed, timely and welcome.

\section{Acknowledgments}

We thank CNPq, especially the support of Felizardo P. da Silva, Silvana M. Cosac and Cristiano L. Kuppens, for the database set up for this research. 


\section{References}

1. Jaffe S. No pardon for poor English in science. The Scientist 2003; 17: 44.

2. Elsevier Editors. Elsevier Editors' Forum. "How Should We Organize Language Polishing and Editing?". Elsevierhttp://www.elsevier. com/wps/find/editorsinfo.editors/editors_update/issue10d; 2006.

3. Hwang K. The inferior science and the dominant use of English in knowledge production. A case-study of Korean science and technology. Sci Commun 2005; 26: 390.

4. Man JP, Weinkauf JG, Tsang M, Sin DD. Why do some countries publish more than others? An international comparison of research funding, English proficiency and publication output in highly ranked general medical journals. Eur J Epidemiol 2004; 19: 811-817.

5. Vasconcelos SMR, Leta J, Sorenson MM. Science in Brazil: $A$ scientometric and linguistic approach. Proceedings of the 10th International Conference of the International Society for Scientometrics and Informetrics. July 24; Stockholm. 2005. p 721.

6. Leta J, Cruz HB. A produção científica brasileira. In: Viotti EB, Macedo MM (Editors), Indicadores de ciência e tecnologia no Brasil. Campinas: Editora Unicamp; 2003.

7. Brazilian National Research Council. Research groups database. CNPq http://www.cnpq.br; 2007.

8. Celani MAA. A retrospective view of an ESP Teacher Education Programme. The ESPecialist 1998; 19: 233-244.

9. Carneiro $S \mathrm{Jr}$, Lourenço R. Pós-graduação e pesquisa na universidade. In: Viotti EB, Macedo MM (Editors), Indicadores de ciência e tecnologia no Brasil. Campinas: Editora Unicamp; 2003. 